\title{
Potato Arabinogalactan Acts as Prebiotics by A Simple Extraction
}

\author{
MASAHIRO Saito $^{1}$ and Masaaki KONISHI ${ }^{2, *}$ \\ ${ }^{1}$ Department of Biotechnology and Environmental Chemistry, Graduate School of Engineering, Kitami Institute of Technology, 165 \\ Koen-cho, Kitami, Hokkaido, 090-8507, Japan. \\ ${ }^{2}$ Biotechnology and Food Chemistry Course Program, School of Regional Innovation and Social Design Engineering, Kitami \\ Institute of Technology, 165 Koen-cho, Kitami, Hokkaido, 090-8507, Japan
}

\begin{abstract}
The effect of the extracting procedures for potato pulp arabinogalactan were investigated on the growth of gut-microflora by in vitro experiments. Crude saccharides (CS) were prepared by $50 \mathrm{~g}$ dried potato pulp suspended in $1 \mathrm{~L}$ of pure water. The suspensions were autoclaved at $121^{\circ} \mathrm{C}$ for $2 \mathrm{~h}$, and filtered by a filter paper. The filtrate were concentrated around $1 / 4$ by a rotary evaporator, and aggregated by $4 \times$ volume of ethanol. Dialyzed saccharides (DS) were prepared to dialyzed CS by a dialysis membrane (cut off MW < 10,000). Enzyme-treated saccharides (ES) were prepared to digest CS by a crude amylase, Gruku-Gin (Amano Enzyme) and dialyzed. All saccharides were lyophilized or heat-dried to store. According to size-exclusion chromatography, the molecular distribution of CS were between 400 and 200,000. A peak of oligosaccharides was observed around MW 800. The peak were disappeared in charts of DS and ES. Glucan were occupied $50 \%$ in the total amount of glycan in CS and DS, and decreased to approx. $5 \%$ in ES. When thirteen strains of gut microbes were cultivated in GAM broth including the saccharides instead of glucose, CP and EP selectively stimulated several non-pathogenic Bifidobacterium and Clostridium, but not pathogenic Enterobacteriaceae.
\end{abstract}

\section{Introduction}

Arabinogalactan-proteins (AGPs) are a family of extensively glycosylated hydroxyproline (Hyp)-rich glycoproteins that are thought to have important roles in various aspects of plant growth and development (Showalter, 2001). AGP core proteins devided into two classes depending upon their core protein: 'classical' and 'nonclassical' AGP. Classical AGPs are defined by the core protein and contain Hyp, Ala, Ser, Thr and Gly as the major amino acid constituents, whereas nonclassical AGPs have their carbohydrate moieties attached to core proteins which are different from classical ones. The carbohydrate moiety of AGPs are rich in arabinose and galactose. The polysaccharide units that are attached to multiple sites on the core protein. The polysaccharide units vary in size from 30-150 sugar residures. Type I arabinogaractan glycan consists of a (1-4)-linked galactan backbone (Hinz et al., 2005). Type II arabinogalactan glycan structure consists of a (1-3)- $\beta$-D-galactan backbone possessing (1-6)- $\beta$-D-galactan side chains. Cterminal glycosylphatidylinositol (GPI) lipid anchor site are observed. AGP are thought to function in various aspects of plant growth and development on the basis of several lines of evidences, i.e., vegetative growth and development, reproductive growth and development, cellular growth and development, and programmed cell death and social control, and molecular interaction and signalling (Showalter, 2001).

AGP derived from white-skinned sweet potate (Ipomoea batatas L.) decrease plasma glucose levels (Oki et al., 2011), and has hypoglycemic effect (Ozaki et al., 2010). In general, AGPs and arabinogaractan (AG) show also prebiotic activities (Hori et al., 2007; Harris et al., 2020), because will balance the microbial composition in the gastrointestinal tract infector of health promoting genera such as Bifidobacterium and Lactobacillus (van den Broek et al., 2008). Terpend et al. (2013) mentioned that AG could be potentially useful to increase the saccharolytic metabolism distally in the colon, by the lactate production stimulated and the positive effect on propionate production both in the stimulated transverse and in the decreasing colon and on butyrate in the simulated desceding colon to improve the concentration of $F$. prausnitzii - a microorganism that can exert antiinflammatory effects. High tolerability of the fibre and specific bifidogenic effect of AG have a potential as interesting product for patients suffering with Irritable Bowel syndrome.

\footnotetext{
* Corresponding author: ikakoh@e-mail.org
} 
Potato pulp, which is high-volume side stream from industrial potato starch, contain $\beta-1,4$ glucan-rich polysaccharides with over $100 \mathrm{kDa}$. The oligosaccharides digested endo-1,4- $\beta$-galactanase from Emericella nidulans enhanced the prebiotics activity (Michalak et al. 2012). However, endo-1,4-galactanase from E. nidulans had been obtained from Pichia pastoris overexpressed the enzyme, because it cannot obtained commercially. Usage of the specialized enzyme would be increase the production cost of potato pulp arabinogalactan (PPA). In this study, simple procedure for producing PPA from potato pulp were performed and prebiotics activities of the obtained PPA were evaluated in vitro cultivation.

\section{Materials and Methods}

\subsection{Materials and microbes}

Potato pulp were kindly provided from Koshimizu branch in Hokkkaido of Japan Agricultural Cooperatives. To store, potato pulp were dried for three days until use. Bifidobacterium adolescentis JCM 1275, Bifidobacterium breve JCM 7016, Bifidobacterium longum JCM 7052, Bifidobacterium longum JCM 7056, Bifidobacterium pseudocatenulatum JCM 1200, Lactobacillus casei JCM 1134, and Lactobacillus gasseri JCM 1131 were purchased from Japan Collection of Microorganism (JCM) of the Microbe Division in RIKEN-BRC. Lactobacillus lactis NBRC 100933, Clostridium butyricum NBRC 3315, Clostridium kainantoi NBRC 3353, Clostridium sporogenes NBRC 13950, Enterococcus faecalis NBRC 100480, and Escherichia coli NBRC 3301 were purchased from National Bio Resource Center (NBRC), in National Institute of Technology and Evaluation (NITE), Japan.

\subsection{Preparation of arabinogalactan from potato pulp}

Grained potato pulp of $50 \mathrm{~g}$ was transfer in $1 \mathrm{~L}$ water to $2-\mathrm{L}$ screw-capped vessel. The vessel was autoclaved at $121^{\circ} \mathrm{C}$ for $1 \mathrm{~h}$. The residues were removed by centrifugation and paper filtration. The filtrate were concentrated to $1 / 5$ volume by a rotary evaporator. 4 vol. of ethanol were added to the concentrate and precipitate were recovered by filtration. The sum of precipitates was dried at $70^{\circ} \mathrm{C}$ and obtained crude saccharide (CS). For preparing dialyzed saccharide (DS), CS was resolved at 5 $\mathrm{g} / \mathrm{l}$ and dialyzed by a cross-flow filter unit (MW > 10,000). For preparing enzyme-treated saccharide (ES), $20 \mathrm{~g} / 1 \mathrm{CS}$ were treated at $45^{\circ} \mathrm{C}$ for $24 \mathrm{~h}$ by a commercial crude amylase (Guruku-Gin, Amano Enzyme Co. Ltd. Japan). After the enzyme treatment, the sample was dialyzed by a cross-flow filter unit $(\mathrm{MW}>10,000)(\mathrm{ES} 1)$ or Wako dialysis membrane $(\mathrm{MW}>10,000)(\mathrm{ES} 2)$.

\subsection{Carbohydrate utilization of gut-microflora in vitro}

Carbohydrate utilization test was performed accoding to Okazaki et al. (1990). The gut microbes were inoculated to GAM broth and incubate at $37^{\circ} \mathrm{C}$ for $24 \mathrm{~h}$. The culture broths $(0.5 \mathrm{ml})$ were transferred to PYF medium (Holdeman et al., 1977) containing 2.0\% (w/v) of saccharides or glucose, and incubated at $37^{\circ} \mathrm{C}$ for 3 days. The utilization of each saccharides was determined on the basis of $\mathrm{pH}$ decrease in the media.

\subsection{Analytical Methods}

\subsubsection{Sugar composition}

Sugar composition was determined by high performance liquid chromatography (HPLC) after acid hydrolysation. For acid hydrolysation, $300 \mathrm{mg}$ of saccharides transfer to $100 \mathrm{ml}$-screw capped vessels and hydrolysed by $3 \mathrm{ml}$ of $72 \%$, w/v sulphuric acid at $30^{\circ} \mathrm{C}$ for $1 \mathrm{~h}$. The hydrolysates were diluted up to $100 \mathrm{ml}$ and autoclaved at $121^{\circ} \mathrm{C}$ for 1 h. The hydrolysates $(5 \mathrm{ml})$ were neutralized by $\mathrm{CaCO}_{2}$. The samples analysed by the following HPLC after filtering by a filter $(0.45 \mu \mathrm{m})$. Sugar compositions were determined by a HPLC system with refractive index (RI) detector. Analytical column Shodex SP0810 was used at $85^{\circ} \mathrm{C}$. Water was used for eluting solution with $0.6 \mathrm{ml} / \mathrm{min}$ of flow rate. Injection volume was set at $10 \mu \mathrm{l}$. Glucose, xylose, arabinose, mannose and galactose was used as standard sugars.

\subsubsection{Molecular weight of saccharides}

To determine the molecular weight distribution of saccharides, size exclusion chromatography were performed. A HPLC system with RI detector equipped TSKgel GMPW (Tosho, Tokyo, Japan). $0.2 \mathrm{~mol} / \mathrm{L}$ sodium phosphate buffer ( $\mathrm{pH}$ 6.8) was used as mobile phase. The flow rate was set at $0.7 \mathrm{ml} / \mathrm{min}$. Pullulan molecular standards (Shodex Co. Ltd. Japan) were used as reference.

\section{Results and Discussion}

\subsection{Effects of extraction procedures on the sugar compositions and molecular weight}

Figure 1A indicates the sugar compositions of saccharides prepared by different procedures. The sugar composition of CS was composed of $35.9 \%$ Galactose, $17.3 \%$, arabinose, and $46.8 \%$ glucose, and the dialysis was no significant effects on the sugar composition. However, amylase treatment and dialysis were decreased drastically glucose composition to $10.8 \%$. The results indicated that most of the glucan was composed of amylose, $\alpha-1,4-$ glucan, because of removing by amylase digression. ES1 were removed well glucan, the composition were galactan and arabinan.

Figure $1 \mathrm{~B}$ indicated the molecular weight distribution of the saccharides. In CS samples, large peak were observed from MW 100 to 1,000 , which seemed to be 
oligosaccharides, which major saccharides would be pentamers to tetramaers. The peak were absent in DS and ES, since that was decreased by dialysis. On the other hand, broad peaks at higher molecular weight in DS and ES were increased compared to CS. The high molecular weight of saccharides would be purified and occupied their composition. Based on the results, amylose would be mostly removed from ES by the amylase. The molecular weight ES2 were corresponded to coffee arabinogaractan (Cof-AG) (Hori et al., 2007). Interestingly, ES1 prepared with cross-flow dialysis membrane unit gave low molecular weight of oligomer peak, but not observed glucan in the sugar composition analysis. ES1 would contained arabinogalactan-oligomer.

Table 1. Sugar composition of saccharides

\begin{tabular}{cccccc}
\hline Saccharides & Glc & Xyl & Gal & Ara & Man \\
\hline CS & 46.8 & n.d. & 35.9 & 17.3 & n.d.- \\
DS & 49.2 & n.d. & 38.4 & 12.4 & n.d. \\
ES1 & n.d. & n.d. & 85.9 & 14.1 & n.d. \\
ES2 & 10.8 & n.d. & 73.9 & 15.3 & n.d.
\end{tabular}

$\mathrm{CS}$, crude saccharides; DS, dialyzed saccharides; ES 1 , enzyme treated and dialyzed by VIVA flow cross flow filtering unit; ES2, enzyme treated and dialyzed by a dialysis membrane

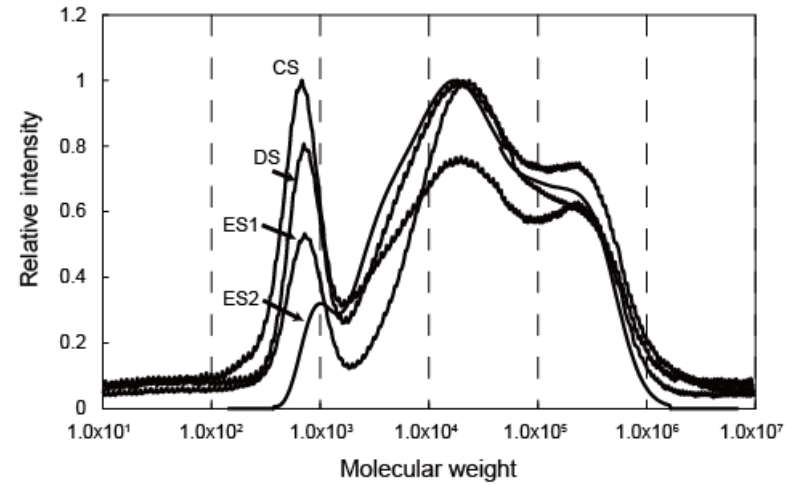

Figure 1. Molecular weight distribution of saccharides

\subsection{Growth stimulation of gut microbes by saccharides}

Growth stimulation of gut microbes by the saccharides are summarized on Table 1. Using glucose as sole carbon source, growths of all tested microbes were stimulated well. Using CS and DS, Bifidobacterium and Lactobacillus gasseri, gut lactic acid bacteria, grew well. All potato saccharides stimulate non-pathogenic Clostridium but not pathogenic $C$. sporogenes. ES1 enhanced also the growth of Lc. lactis and Lc. cassei, however ES2 no longer stimulate their growths. Enterococcus and Escherichia were never stimulated by the potato saccharides. The difference of growth stimulation effects on the gut microbes would be dependent on the presence of AG oligomer in the culture broths. The growth stimulation effects of type I potato AG were slightly different from that of type II AG (Hori et al., 2007), in the growth stimulation for non-pathgenic Clostridium sp. and part of Bifidobacterium and Lactobaccilus. Furthermore, CS show the good prebiotics activities in broad ranges of Bifidobacterium, and the other LAB. The result implied that the CS can give the prebiotics activities in vivo, without costly enzyme treatments. Moreover, since ES1 indicated growth stimulation for broad ranges of LABs, AG oligosaccharides accelerate the prebiotics activities. The results implied simple heat extraction were promising technique for potato AG prepared as prebiotics. Now, we are investigating effects of subcritical water on the qualities and prebiotics activities of $A G$ extracted by the subcritical water to control molecular weight of AG.

Table 2. Formatting sections, subsections and subsubsections

\begin{tabular}{|c|c|c|c|c|c|c|c|}
\hline Strains & Glc & $\mathrm{CS}$ & DS & ES1 & ES2 & $\begin{array}{l}\text { Cof- } \\
\text { Ag* }^{*}\end{array}$ & $\begin{array}{c}\text { L- } \\
\text { AG } \\
*\end{array}$ \\
\hline$B$ & & & & & & & \\
\hline $\begin{array}{l}\text { adolescentis } \\
\text { JCM } 1275\end{array}$ & ++ & ++ & ++ & + & - & - & - \\
\hline $\begin{array}{c}\text { B. breve JCM } \\
7016\end{array}$ & ++ & ++ & ++ & + & + & - & $+/-$ \\
\hline $\begin{array}{l}\text { B. longum } \\
\text { JCM } 7052\end{array}$ & ++ & + & + & ++ & $+/-$ & ++ & ++ \\
\hline $\begin{array}{l}\text { B. longum } \\
\text { JCM } 7056\end{array}$ & ++ & + & + & ++ & $+/-$ & ++ & ++ \\
\hline $\begin{array}{c}B . \\
\text { pseudocatenl } \\
\text { atum JCM } \\
1200\end{array}$ & ++ & ++ & ++ & + & - & ++ & $+/-$ \\
\hline $\begin{array}{l}\text { Lb. casei } \\
\text { JCM } 1134\end{array}$ & ++ & - & - & + & - & - & - \\
\hline $\begin{array}{l}\text { Lb. gasseri } \\
\text { JCM } 1131\end{array}$ & ++ & + & + & + & - & - & - \\
\hline Lc. lactics & & & & & & & \\
\hline $\begin{array}{l}\text { NBRC } \\
100933\end{array}$ & ++ & - & - & + & - & - & - \\
\hline $\begin{array}{l}\text { C. butyricum } \\
\text { NBRC } 3315\end{array}$ & ++ & ++ & ++ & + & + & - & - \\
\hline $\begin{array}{l}\text { C. kainantoi } \\
\text { NBRC } 3353\end{array}$ & ++ & ++ & ++ & + & $+/-$ & - & - \\
\hline $\begin{array}{l}\text { C. sporogenes } \\
\text { NBRC } 13950\end{array}$ & ++ & - & - & - & - & - & - \\
\hline En. faecalis & & & & & & & \\
\hline $\begin{array}{l}\text { NBRC } \\
100480\end{array}$ & ++ & - & $+/-$ & - & - & - & - \\
\hline $\begin{array}{c}\text { Es. Coli } \\
\text { NBRC } 3301\end{array}$ & + & - & - & - & - & - & - \\
\hline
\end{tabular}

CS, crude saccharides; DS, dialyzed saccharides; ES1, enzymetreated saccharides and dialysis by VIVA flow cross flow filtering unit; ES2, enzyme-treated saccharides and dialysis by dialysis membrane. Cof-AG, arabinogaractan from coffee beans; L-AG, Arabinogalactan from larch wood.

* Results by Hori et al. (2007)

Judgement of bacterial growth: $(-), \Delta \mathrm{pH}<0.5,(+/-), 0.5 \leq$ $\Delta \mathrm{pH}<1.0 ;(+), 1.0 \leq \Delta \mathrm{pH}<1.5,(++), 1.5 \leq \Delta \mathrm{pH} . \Delta \mathrm{pH}$ defined as differences of $\mathrm{pH}$ with and without test strain.

\section{Acknowledgements}

We thanks to JA Koshimizu, Hokkaido, for kindly providing of potato pulp samples. 


\section{References}

Harris, S., S Powers, A Monteagudo-Mera, O Kosik, Lovegrove A., and P. Shewry; "Determination of the Previotic Activity of Wheat Arabinogalactan Peptide (AGP) Using Batch Culture Fermentation," Euro. J. Nutr., 59, 297-307 (2020)

Holdeman, L.V., E. P. Cato and W. E. C. Moore; Anaerobic Labratory Manual, 4th ed., Anaerobe Laboratory, Virginia Polytechnic Institute and State University, Blacksburg, USA (1977)

Hori, M., K. Iwai, R. Kimura, O. Nakagiri, and M. Takagi; "Utilization by Intestinal Bacteria and Digestibility of Arabinogaractan from Coffee Bean in vitro," (in Japanese) Jpn. J. Food Microbiol. 24, 163-170 (2007)

Hinz, S. W. A., R. Verhoef, H. A. Schols, J.-P. Vincken and A. G. J. Voranen; "Type I Arabinogalactan Contains $\beta$-D-Galp-(1-3)- $\beta$-D-Galp Structural Elements," Carbohydr. Res., 340, 2135-143 (2005)

Showalter, A. ; "M. Arabinogalactan-proteins : Structure, Expression and Function," A. CMLS, Cell. Mol. Life Sci., 58, 1399-1417 (2001)

Michalak, M., L. V. Thomassen, H. Roytio, A. C. Ouwehand, and A. S. Meyer; "Expression and Characterization of an endo-1,4- $\beta$-galactanase from Emericella nidulans in Pichia pastoris for Enzymatic Design of Potentially Prebiotic Oligocaccharides from Potato Galactans," Enzyme Microbial. Technol., 50, 121129 (2012)

Okazaki, M., S. Fujikawa, and N. Maumoto ; "Effect of Xylooligosaccharide on the Growth of Bifidobacteria," Bifidobacteria Microflora., 9, 77-86 (1990)

Oki, N., S. Nonaka, and S. Ozaki ; "The Effects of Ana Arabinogalactan-Protein from teh White-Skinned Sweet Potato (Ipomoea batatas L.) on Blood Glucose in Spontaneous Diabetic Mice," Biosci. Biotechnol. Biochem.,75, 596-598 (2011)

Ozaki, S., N. Oki, S. Suzuki and S. Kitamiura; "Structural Characterization and Hypoglycemic Effects of Arabinogalactan-Proteun from the Tuberous Cortex of the White-Skinned Sweet Potato (Ipomoea batatas L.)," J. Agric Food Chem., 58, 11593-11599 (2010)

Terpend, K., S. Possemiers, D. Daguet, and M. Marzorati ; "Arabinogalactan and Fructooligosaccharides Have a Different Fermentation Profile in the Simulator of teh Human Intestinal Microbial Ecosystem (SHIME(R))," Environ Microbiol Rep., 5, 595-603 (2013)

van den Broek, L. A., S. W. Hinz, G. Beldeman, J. P. Vicken, and A. G. Voragaen; "Bifidobacterium Carbohydrates-their Role in Breakdown and Synthesis of (potential) Prebiotics," Mol. Nutr. Food Res., 52, 164-163 (2008)

\footnotetext{
Corresponding author: ikakoh@e-mail.org
} 